\title{
Mapping Psychosocial Risk and Protective Factors in Suicidal Older Persons-A Systematic Review
}

\author{
Anne Lise Holm1, Elisabeth Severinsson² \\ ${ }^{1}$ Department of Health Science, Stord/Haugesund University College, Haugesund, Norway \\ ${ }^{2}$ Centre for Women's, Family and Child Health, Faculty of Health Sciences, Buskerud and Vestfold University \\ College, Drammen, Norway \\ Email: anne.holm@hsh.no, elisabeth.severinsson@hbv.no
}

Received 10 March 2015; accepted 24 March 2015; published 27 March 2015

Copyright (C) 2015 by authors and Scientific Research Publishing Inc.

This work is licensed under the Creative Commons Attribution International License (CC BY).

http://creativecommons.org/licenses/by/4.0/

(c) (i) Open Access

\section{Abstract}

Social disconnectedness in combination with depression, somatic disease, stigma, social exclusion and functional impairment has been described as a major risk factor for suicide in old age. However, protective factors have not been focused on in the same way. The aim was to identify psychosocial risk and protective factors in suicidal older persons. A systematic review was performed in Academic Search Premier (34), Ovid Medline (0), PsycInfo (0), PubMed (66), CINAHL (3) and ProQuest (1078) for the period May - September, 2014. Results: Twelve studies were included in the final analysis. Psychosocial risk factors were categorized under four themes: Being a burden to others increases depression and hopelessness, the struggle due to poor social integration, the strain of physical illness and old age and Negative aspects of religious activity. A total of four protective factors emerged: a sense of belonging, maintaining social dignity, satisfaction with relationships and feeling useful and positive aspects of religious activity. In conclusion, the context of a suicidal older person in a home healthcare service may create a "vulnerable psychosocial state" in which she/he is confronted by stressful psychosocial life events including physical illness and social network changes. The fact that protective factors are solely related to social factors needs to be taken into account in future prevention studies.

\section{Keywords}

Older, Protective Factors, Psychosocial Risk Factors, Suicide

\section{Introduction}

The World Health Organization [1] reports that suicide in older adults is a global health problem. The over-65 
year age group has the highest suicide rate in most countries that report suicide statistics to the WHO [2]. Countries with high rates of older adult suicide include European Union states, Canada, the US and some Asian countries such as Japan, Singapore and Taiwan. In many countries, older adult suicidal behaviour is lethal, as nonfatal suicidal acts tend to be less common in this age group [3]. In the US, up to $75 \%$ of older adults die as a consequence of their first suicide attempt [4]. Mental disorder is present in $71 \%-97 \%$ of older adults who die by suicide, depression being the most common diagnosis [4]. A meta-analysis showed reduced suicide rates in several communities that were exposed to interventions in Japan, particularly in women [5]. The available literature indicates various predictors of suicide in old age [6] [7]. Stressful life events such as the loss of one's spouse have been found to have a significant correlation with increased suicide risk in older adults [8]. Qualitative studies have revealed that the participants experience the final phase of life as a burden and seem to accept death [9] [10]. Rurup et al. [11] stated that the older persons in their study gradually developed suicidal ideation after a life full of adversity and as a consequence of ageing, illness or recurring depression. Holm et al. [12] described that the older participants in their study experienced the situated meaning of survival as "shadows from the past" - a feeling that something inside is broken, forcing them to struggle to catch the light. Joiner [13] develops the Interpersonal Theory of Suicide (ITS), which proposes that in order to complete suicide, one must have both the desire and ability to carry out the act. Desire for suicide contains two important components: perceived burdensomeness to others and a thwarted sense of belongingness [13]. Joiner's [13] states that the desire for suicide arises when a person perceives her/himself to be a burden on significant others. In addition, she/he must have a sense of thwarted belongingness, or lack of social connectedness through meaningful relationships [13].

Collaborative care models for depression involving expert mental health consultation, medication recommendations, psychotherapy and psycho-education have reduced suicidal ideation among older adults in the US [14] [15]. In Norway, a qualitative implementation project using the Chronic Care Model (CCM) revealed psychosocial aspects such as stigma and social exclusion that can increase suicidal behaviour in depressed older persons in the community [16]-[18]. The systematic review by Fässberg et al. [2] demonstrates that most depressed older people do not die by suicide and that there are modifiable risk markers that can be targeted before the emergence of depression, suicidal feelings and other risk factors for suicide mortality. Social factors constituted important aspects in this context [2]. Carli et al. [19] state that the strongest predictors of serious suicidal behaviors (SSB) seem to be older age and not professing a religion. A review by Van Orden and Conwell [20] reveals that social disconnectedness in combination with depression, somatic disease and functional impairment is a major risk factor for suicide.

There remains a paucity of research on the specific contribution of psychosocial aspects to suicidal ideation in older adults. Studies have used various social support constructs (i.e., social network, social interaction, social isolation and family discord) that include objective and subjective measures. Few studies employed different types of social support indices as predictors of suicidal ideation in older adults. Social aspects associated with suicidal ideation in older adults include a limited social network and living arrangements that allow few contacts with friends or relatives [21] [22]. Lack of self-confidence and social support are also reported [23] [24].

\section{Aim}

The aim of this study was to identify psychosocial risk and protective factors in suicidal older persons. The research question was: What psychosocial risk and protective factors for suicidal older persons are found in the literature?

\section{Methods}

We systematically searched for and synthesized evidence of psychosocial risk and protective factors in suicidal older persons [25].

\subsection{Inclusion and Exclusion Criteria}

The studies, which were published between September 2004 and September 2014, included older adults aged 59 years and over. The inclusion criteria were: published in English language peer-reviewed journals and investi- 
gating psychological aspects such as suicidal ideation, distress, emotional pain, depression as well as social aspects of relationships, social support, social networks and social inclusion. The exclusion criteria were review studies, qualitative studies, theoretical studies, studies of younger suicidal persons, studies published before 2004 and implementation studies.

\subsection{Literature Search}

Electronic searches were performed in Academic Search Premier (34), Ovid Medline (0), PsycInfo (0), PubMed (66), CINAHL (3) and ProQuest (1078) for the period May - September 2014. The search words were: Depression, distress, older, social network, social relationships, social support and suicide ideation. A total of 1,181 abstracts were read and 37 studies retrieved for further investigation. A manual search yielded four studies. The abstracts included review papers, non-empirical research and theoretical studies that did not fulfil the inclusion criteria. The retrieval and selection process, which resulted in a total of twelve quantitative studies, are presented in Figure 1.

\subsection{Evaluation of the Included Studies}

The studies comprised a broad spectrum of content, various outcome measurements and different statistical analyses across diverse time periods, making a meta-analysis impossible [26]. A key dimension of any systematic review is an examination of the methodologies of the primary studies [26] [27], which were assessed on the basis of the PRISMA [28] checklist, according to which it is important to review methodological procedures such as validity, reliability, generalization and rigour. We also reviewed methodological aspects (see Table 1) of the design, sample size, response rate, causality, measurements, generalization and ethical approval [27] [29].

Design; Five studies described the design as cross-sectional [30]-[34]. One study was part of a larger casecontrol study [35], while another used a longitudinal design [36]. Five studies contained no information about

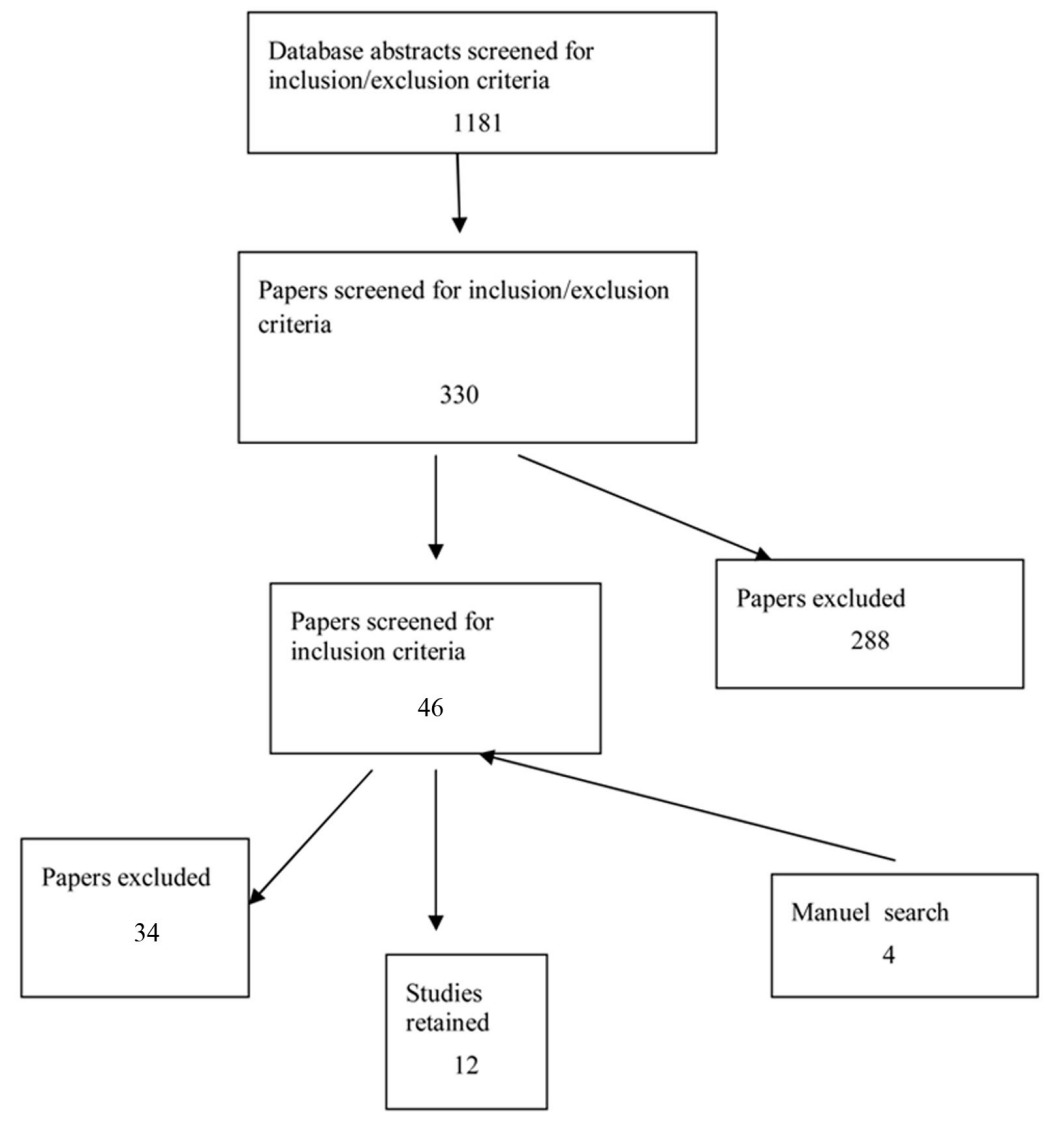

Figure 1. Search and retrieval process. 
Table 1. Psychosocial risk and protective factors in suicidal older persons.

\begin{tabular}{|c|c|c|c|}
\hline $\begin{array}{l}1^{\text {st }} \text { author, year, } \\
\text { country }\end{array}$ & Aim & $\begin{array}{l}\text { Design, measurements, } \\
\text { analysis }\end{array}$ & Summary of outcomes \\
\hline $\begin{array}{l}\text { 1) Cukrowicz et al. } \\
\text { (2011) } \\
\text { USA }\end{array}$ & $\begin{array}{l}\text { To test the association of } \\
\text { perceived burdensomeness on } \\
\text { suicidal ideation in older } \\
\text { adults. }\end{array}$ & $\begin{array}{l}\text { Cross-sectional } \\
\text { INQ, GSIS-SI, CESD, } \\
\text { UCLA (study 1), BHS, } \\
\text { SF-8, SPSS Version } \\
17.0 \text { (study 1). } \\
\text { Descriptive statistics } \\
\text { (study 2). }\end{array}$ & $\begin{array}{l}\text { The results suggest that perceived burdensomeness } \\
\text { accounts for significant variance in suicidal } \\
\text { ideation, even after controlling for predictors such } \\
\text { as depression, hopelessness and functional } \\
\text { impairment. }\end{array}$ \\
\hline
\end{tabular}

$\begin{array}{ll} & \text { To determine clinical factors } \\ \text { 2) Dennis et al. } & \text { that might help to identify } \\ \text { (2005) } & \text { older adults with depression } \\ \text { UK } & \text { who are most at risk of } \\ & \text { self-harm and suicide. }\end{array}$

3) Harrison et al. (2010)

UK

4) Heisel \& Flett (2008) CANADA

5) Jahn et al. (2011) USA

6) McLaren et al. (2007) AUSTRALIA

7) Mellqvist et al. (2011) SWEDEN
To explore the relationship between suicidal thoughts/attempts, social support and chronic interpersonal difficulties.

Design not specified BDI, BHS, GDS, LEDS, SCS, SIS. Statistical Package, version 10 Windows.

Cross-sectional BHS, BLS, CIRS-G, HRSD, ISEL, IIP, HRSD, SCID SAS software version 9, Analysis of variance (ANOVA).

It was hypothesized that suicidal ideation was positively associated with depression and a number of self-reported health problems and negatively with domains of psychological wellbeing and meaning in life.

It was hypothesized that perceived burdensomeness mediates the relationship between depressive symptoms and suicidal ideation in a community sample of older adults.

To examine the applicability of the compensatory, the risk-protective, the challenge and the protective-protective models of resiliency for the prediction of suicidal ideation associated with depression and sense of belonging among older adults.
Cross-sectional MMSE, GSIS GDS, PWB, PIL, SNS Descriptive statistics, Windows.

Design not specified GSIS, MSSI, bivariate correlations.

Design not specified ZD, SBI-33, GHQSS, regression analysis. SPSS version 14.0 for CES-D, SCS, BHS,

Descriptive statistics and Descriptive statistics and

Social factors, hopelessness and depression in a group of older persons referred to primary care following an episode of self-harm compared with similarly aged persons with depression with no history of self-harm.

Suicidal depressed older persons reported the lowest levels of perceived social support (belonging, tangible support and self-esteem) and higher levels of chronic interpersonal difficulties (struggle against others and interpersonal hostility) compared with both non-suicidal depressed and non-depressed older persons.

The main findings indicated that suicidal ideation was positively associated with depression and self-reported physical health problems and negatively with domains of psychological well-being including positive relations with others, self-acceptance and perceived meaning in life.

Perceived burdensomeness mediated the relationship between depression and suicidal ideation, accounting for $68.3 \%$ of the variance suicidal.

When sense of belonging (psychological) was the protective factor, the results indicated support for the risk-protective model for men and women as well as the compensatory model for women. In contrast, when sense of belonging (antecedents) was the protective factor, support was evident for the compensatory model for men and women as well as for the challenge model for women.

There was a strong relationship between major depression and SOC. While the authors could show no relationship between severe physical illness and SOC, associations with social variables were demonstrated, including too little time spent with children, too little time spent with grandchildren and having moved within the past five years. These associations remained significant in regression models adjusted for sex, age and major depression. 


\section{Continued}

8) Rushing et al. religious involvement, above and

(2012)

USA

beyond the protective effects of

social support, on current and

past suicidality among depressed older adults.

To examine the associations

9) Rowe et al.

(2006)

USA between objective and subjective social support and suicidal ideation in older adults receiving home healthcare services.
Design not specified NCODE, DDES, DSM-IV, MADRS, DIS, DSSI.

Descriptive statistics and regression analysis.
Factors associated with less suicidal ideation were past history of suicide attempts, four religious involvement indicators, social support indicators, private religious practices and perceived social support, the latter partly acting as a mediator. Current religious practices were not predictive of retrospective reports of past suicide attempts. Church attendance, rather than other religious involvement indicators, had the strongest relationship with current suicidal ideation.

Lower social interaction patterns and lower perceived social support were significantly related to suicidal ideation. Lower perceived support was significantly associated with suicidal ideation. Satisfaction with one's relationships and feeling useful to family and friends were significantly associated with a lower likelihood of suicidal ideation in the final regression model.

The high prevalence of death ideation (6.9\% for men and $13.0 \%$ for women) confirmed that it is linked to elders' suicidal behaviour and thus a major public health issue. The analyses revealed a strong association between community participation and death ideation. When adjusted for depression, the model identified factors significantly associated with death ideation; being elderly, especially over 84, retired for fewer than five years, widowed and having a long-term illness.

Suicide attempters committed significantly more errors in social emotion recognition and exhibited poorer global cognitive performance than elders with no psychiatric history. Attempters had limited social networks: were less likely to talk to their children, had fewer close friends and did not engage in voluntary activities compared to non-suicidal depressed elders and those with no psychiatric history.

The results indicated that fewer social support resources were associated with higher levels of depression and suicidal ideation. Sense of belonging to the community was not a predictor of mental health. The results suggest that enhancing social support resources in older adults could reduce depression and suicidal ideation.
12) Vanderhorst \& McLaren (2010)

Australia
The study investigated the human relatedness variables of marital status, social support resources and sense of belonging as predictors of depression and suicidal ideation in older adults.
SSSCRI, SBI, ZDS,

SSGHQ.

Regression analysis.

List of abbreviations: BHS (Beck Hopelessness Scale), BDI (Beck Depression Inventory), BLS (Beck Lethality Scale, CESD (Center for Epidemiologic Studies-Depression Scale), CI (Chronic illness), CIRS-G (Cumulative Illness Rating Scale for Geriatrics), CPRS (Comprehensive Psychopathological Rating Scale), DAFA (Direct Assessment of Functional Abilities), DDES (Depression Evaluation Schedule), DIS (Diagnostic Interview Survey), DSSI-23 (Abbreviated Duke Social Support Index), EURO-D12 (Continuous score number of depressive symptoms) for evaluating depression.GDS (Geriatric Depression Scale), GSIS-SI (Geriatric Suicide Ideation Scale-Suicide Ideation Subscale), GHQSS (General Health Questionnaire Suicide Subscale), HRSD (Hamilton Rating Scale for Depression), ISEL (Measures of Perceived Social Support), IIP (Chronic Interpersonal Difficulties), INQ (The Interpersonal Needs Questionnaire), LEDS (Life Events and Difficulties Schedule), LS (Loneliness Scale), LS (Beck Lethality Scale), MADRS (Montgomery-Asberg Depression Rating Scale), MMSE (Mini-Mental State Examination), MSPSS (Multidimensional Scale of Perceived Social Support), MSSI (a clinical-administered interview used to assess suicidal risk), NCODE (NeuroCognitive Outcomes of Depression in the Elderly), PHQ-9 (Patient Health Questionnaire), PPHP (Perceived Physical Health Problems), PIL (Purpose in Life), PWB (Psychological Well-Being), RAO (religious affiliation and observance, an open ended questionnaire), RI (Religion indicators), RME (Social Emotion Recognition), SBI (Sense of Belonging Instrument), SCS (Suicide Cognitions Scale), SCID (Structured Clinical Interview for Diagnostic and Statistical Manual of Mental Disorder), SF-8 (The Medical Outcomes Study Short Form General Health Survey-8), SGDS (Geriatric Depression Scale), SHARE (study of Health, Ageing and Retirement in Europe), SISE (Single-Item Self-Esteem Scale), SN (Social Network), SNS (Social Network Self-report), SIS (Suicide Intent Scale), SOBI-P (Sense of Belonging Instrument-Psychological Experience Subscale), SOC (Sense of Coherence Scale), SRH (Self-rated Health), SS (Social situation scale), SSGHQ (Suicide Subscale of the General Health Questionnaire), SSI (Scale for Suicide Ideation), SSSCRI (Social Support Subscale of the Coping Resources Inventory), UCLA (The UCLA Loneliness Scale), WHODAS.II.K (Word Health Organization Disability Assessment Schedule), ZDS (Zung Depression Scale). 
the design [37]-[41].

The sample size of the studies ranged from 80 to 522 persons (Table 2) except for the survey by Saias et al. [36] that included 11,425 older subjects. The mean age of the participants ranged from 59 - 102 years. Five studies had a response rate of between 50\% and 77.4\% (median 66.8\%) [30] [35] [36] [38] [39]. Seven studies had no information about the response rate [31] [34] [37] [40] [41].

Causality; Six studies described the impossibility of inferring any causal relationship between variables [30] [32] [34] [39]-[41]. Rowe et al. [30] explained that causal relationships cannot be established given the crosssectional nature of the data. Six studies did not discuss the causal role and its influence on internal validity [31] [33] [35]-[38].

Measurements; Two studies demonstrated the validity and reliability of some of the measurements used [31] [35] while five presented the validity and reliability of all measurements [32] [38]-[41]. McLaren et al. [39] stated that their data were collected through self-reports from the same source. Jahn et al. [40] noted that self-report measures might not be as sensitive to a full range or history of symptoms as a clinician administered interview measure. The questionnaires did not include an indication of over or underreporting [40]. Five studies provided no description of the validity or reliability of the measurements used [30] [33] [34] [36] [37]. Mellqvist et al. [35] stated that the Comprehensive Psychopathological Rating Scale (CPRS) was based on good reliability and validity in elderly clinical samples. All ratings were made by the same research psychologist and found to have high inter-rater agreement with those of psychiatrists and research nurses [35].

Generalization; Eight studies described limitations to generalizing the findings to older adults in other settings and cultures [30] [32] [33] [35] [38]-[41]. In three studies, it was explained that the sample was mainly white [30] [33] [41]. Cukrowicz et al. [32] stated that a characteristic of the sample could limit generalizing the findings as the participants were not members of a group particularly at risk of suicide, other than their age and presentation to primary care. Two studies had samples that were predominantly female, which could limit generalization [33] [38]. Four studies did not mention generalization to other older persons [31] [34] [36] [37].

Ethical approval; Six studies were approved by an institution, hospital and/or university review board [30] [31] [33]-[35] [41]. Six studies contained no information about ethical approval [32] [36]-[40].

Demographic data; All the included studies contained some demographic data (see Table 2). In addition, four studies provided information about sex, age and educational level [31] [36] [38] [39]. Vanderhorst \& McLaren [37] stated that sex, age and highest educational level played a significant role in the occurrence of depression. McLaren et al. [39] revealed that females reported significantly higher levels of suicidal ideation. Heisel and Flett [31] demonstrated that in men with a high sense of belonging (psychological), suicidal ideation is similar to that of women, irrespective of the level of depression. In contrast, suicidal ideation in men with a low sense of belonging is high when levels of depression are high. When controlling for age and sex, Heisel and Flett [31] found a strong association between these factors and suicide-related mortality. Controlling for psychogeriatric patient status led to a significant association between these variables. Saias et al. [36] described that women with less than 12 years of education and participants receiving insufficient income or suffering from a chronic illness were more at risk of exhibiting death ideation.

\subsection{Data Analysis}

The methods of analysing a systematic review can be either statistical (meta-analysis) or qualitative (meta-synthesis), depending on the purpose and the material involved [42]. The authors of the present review investigated psychosocial risk and protective factors in suicidal older individuals using a qualitative thematic analysis to produce a meta-synthesis. In this process they identified, grouped and summarized the findings as described by Pope et al. [43]. The synthesis included quantitative data, in which the themes emerged from the analysis process. The themes were identified by reading and re-reading the studies in order to synthesize the findings [42]. Using words and text, the authors identified different patterns and concepts across the data. This process led to common meanings that can be considered descriptions of psychosocial risk factors. However, when searching for risk factors several protective factors also emerged. Thus the authors differentiated psychosocial risk factors from protective factors and presented a meta synthesis of these two types of factor in Table 3. The authors discussed the themes and subthemes several times before reaching consensus on the labelling. 
Table 2. Demographic characteristics.

\begin{tabular}{|c|c|c|c|c|}
\hline $1^{\text {st }}$ author, year & Sex & Sample, age & Marital status & Context/inpatients \\
\hline $\begin{array}{l}\text { 1) Cukrowicz } \\
\text { et al. (2011) } \\
\text { USA }\end{array}$ & $\begin{array}{l}32 \text { women } \\
25 \text { men (study 1) } \\
78 \text { women } \\
27 \text { men (study 2) }\end{array}$ & $\begin{array}{l}\mathrm{N}=162 \\
\mathrm{~N}=57(\text { study } 1) \\
\mathrm{N}=105 \text { (study } 2) \\
\text { Median } 74.14 \\
\text { Median } 70.89\end{array}$ & $\begin{array}{l}62 \% \text { married/living with a partner, } \\
22 \% \text { widowed, } 16 \% \\
\text { divorced/separated/never married. }\end{array}$ & No information \\
\hline $\begin{array}{l}\text { 2) Dennis et al. } \\
\text { (2005) } \\
\text { UK }\end{array}$ & $\begin{array}{l}56 \text { women } \\
44 \text { men }\end{array}$ & $\begin{array}{l}N=126 \\
N=76 \\
N=50 \text { comparison group } \\
65 \text { years and over } \\
\text { Median } 76\end{array}$ & $\begin{array}{l}71 \% \\
52 \%\end{array}$ & No information \\
\hline $\begin{array}{l}\text { 3) Harrison et } \\
\text { al. (2010) } \\
\text { UK }\end{array}$ & No information & $\begin{array}{l}N=87 \\
N=29 \\
N=58 \text { comparison group } \\
60 \text { years and older }\end{array}$ & No information & $\begin{array}{l}\text { Psychogeriatric clinic. } \\
\text { Comparison group living } \\
\text { in the } \\
\text { community }\end{array}$ \\
\hline $\begin{array}{l}\text { 4) Heisel \& } \\
\text { Flett (2008) } \\
\text { Canada }\end{array}$ & $\begin{array}{l}71 \text { women } \\
36 \text { men }\end{array}$ & $\begin{array}{l}\mathrm{N}=107 \\
\text { Mean age } 81.4 \text { years range } \\
\text { Age } 67 \text { to } 98 \text { years }\end{array}$ & 77\% unmarried & $\begin{array}{l}\text { Psychogeriatric clinics. } \\
\text { Nursing homes. General } \\
\text { hospitals, retirement } \\
\text { residences }\end{array}$ \\
\hline $\begin{array}{l}\text { 5) Jahn et al. } \\
\text { (2011) } \\
\text { USA }\end{array}$ & $\begin{array}{l}78 \text { women } \\
28 \text { men }\end{array}$ & $\begin{array}{l}\mathrm{N}=106 \\
\text { Age } 60-93 \\
\text { Mean age } 70.9\end{array}$ & $\begin{array}{l}58.1 \% \text { married } \\
21.9 \% \text { widowed, } 11.4 \% \text { divorced, } \\
4.8 \% \text { living with a partner, } 1.9 \% \text { in } \\
\text { a relationship, but not living } \\
\text { together }\end{array}$ & $\begin{array}{l}\text { Community and Family } \\
\text { Medicine clinic }\end{array}$ \\
\hline $\begin{array}{l}\text { 6) McLaren et } \\
\text { al. (2007) } \\
\text { Australia }\end{array}$ & $\begin{array}{l}221 \text { women } \\
130 \text { men }\end{array}$ & $\begin{array}{l}\mathrm{N}=351 \\
\text { Mean age } 71.31 \text { years }\end{array}$ & $\begin{array}{l}80 \% \text { of the men were married and } \\
69 \% \text { lived in their own home with } \\
\text { another person. } 48 \% \text { of the women } \\
\text { were married, } 42 \% \text { were widowed, } \\
43 \% \text { lived in their own home with } \\
\text { another person, } 32 \% \text { lived in a } \\
\text { retirement village, and } 20 \% \text { lived } \\
\text { alone }\end{array}$ & $\begin{array}{l}\text { Retired Australians, living } \\
\text { in the community }\end{array}$ \\
\hline $\begin{array}{l}\text { 7) Mellqvist et } \\
\text { al. (2011) } \\
\text { Sweden }\end{array}$ & $\begin{array}{l}42 \text { women } \\
38 \text { men }\end{array}$ & $\begin{array}{l}\mathrm{N}=80 \\
\text { Mean age } 79.4 \text { years } \\
\text { Participation rate } 77.4 \%\end{array}$ & $\begin{array}{l}51 \text { of the sample lived without a } \\
\text { partner. } 15 \text { were divorced, } 35 \text { were } \\
\text { widowers or widows, } 72 \text { had } \\
\text { children, } 26 \text { lived alone }\end{array}$ & $\begin{array}{l}\text { Most of the interviews } \\
\text { were conducted in a } \\
\text { hospital, but } 14 \text { were held } \\
\text { after discharge }\end{array}$ \\
\hline $\begin{array}{l}\text { 8) Rusing et al. } \\
\text { (2012) } \\
\text { USA }\end{array}$ & $\begin{array}{l}168 \text { women } \\
80 \text { men }\end{array}$ & $\begin{array}{l}\mathrm{N}=248 \\
59 \text { years or older } \\
\text { Mean age } 59-96(70.0)\end{array}$ & $\begin{array}{l}57.7 \% \text { were married, } 42.3 \% \text { were } \\
\text { not married }\end{array}$ & $\begin{array}{l}\text { Inpatient or outpatient } \\
\text { psychiatry services at a } \\
\text { Medical Centre or Clinic }\end{array}$ \\
\hline $\begin{array}{l}\text { 9) Rowe et al. } \\
\text { (2006) } \\
\text { USA }\end{array}$ & $\begin{array}{l}342 \text { women } \\
180 \text { men }\end{array}$ & $\begin{array}{l}N=522 \\
65-102 \text { years }\end{array}$ & No information & Living at home \\
\hline $\begin{array}{l}\text { 10) Saias et al. } \\
\text { (2012) } \\
\text { France }\end{array}$ & $\begin{array}{l}6213 \text { women } \\
5227 \text { men }\end{array}$ & $\begin{array}{l}\mathrm{N}=11.140 \\
64 \text { years and over }\end{array}$ & $\begin{array}{l}7262 \text { married, } 584 \\
\text { divorced/separated, } 479 \text { single, } \\
3033 \text { widowed }\end{array}$ & \\
\hline $\begin{array}{l}\text { 11) Szanto et } \\
\text { al. (2012) } \\
\text { UK }\end{array}$ & $\begin{array}{l}56 \text { women } \\
34 \text { men }\end{array}$ & $\begin{array}{l}\mathrm{N}=90 \\
\mathrm{~N}=24 \text { depressed suicide } \\
\text { attempters, } \\
\mathrm{N}=38 \text { non-suicidal } \\
\text { depressed elders, } \\
\mathrm{N}=28 \text { no psychiatric } \\
\text { history. } \\
\text { Mean age } 68.2\end{array}$ & $\begin{array}{l}42 \% \text { married in the suicide group } \\
(\mathrm{N}=24), 39 \% \text { in the non-suicidal } \\
\text { depressed group }(\mathrm{N}=38) \text {, and } \\
57 \% \text { in the non-psychiatric control } \\
\text { group, } \mathrm{N}=28\end{array}$ & $\begin{array}{l}\text { Inpatient psychogeriatric } \\
\text { unit. Late life depression } \\
\text { clinic. University and } \\
\text { community primary care } \\
\text { practices }\end{array}$ \\
\hline $\begin{array}{l}\text { 12) } \\
\text { Vanderhorst \& } \\
\text { McLaren } \\
\text { (2010) } \\
\text { Australia }\end{array}$ & $\begin{array}{l}87 \text { women } \\
23 \text { men }\end{array}$ & $\begin{array}{l}\mathrm{N}=110 \\
65 \text { years and older. } \\
\text { Mean age } 75 \text { years }\end{array}$ & $\begin{array}{l}38 \% \text { married, } 53 \% \text { widowed, } 2 \% \\
\text { divorced and } 7 \% \text { single }\end{array}$ & $\begin{array}{l}\text { Living in a retirement } \\
\text { village, their own home or } \\
\text { a nursing home }\end{array}$ \\
\hline
\end{tabular}


Table 3. Summary of the results of the thematic analys.

\begin{tabular}{cc}
\hline Psychosocial risk factors & Protective factors \\
\hline Being a burden to others increases depression and hopelessness & A sense of belonging \\
The struggle due to poor social integration & Maintaining social dignity \\
The strain of physical illness and old age & Satisfaction with relationships and feeling useful \\
Negative aspects of religious activity & Positive aspects of religious activity \\
\hline
\end{tabular}

\section{Results}

The psychosocial risk factors were categorized under four themes: Being a burden to others increases depression and hopelessness, The struggle due to poor social integration, The strain of physical illness and old age and Negative aspects of religious activity. In terms of protective factors four themes emerged: A sense of belonging, maintaining social dignity, satisfaction with relationships and feeling useful and Positive aspects of religious activity.

\subsection{Psychosocial Risk Factors}

\subsubsection{Being a Burden to Others Increases Depression and Hopelessness}

One psychosocial risk factor was described as perceiving oneself as a burden to others, which increases depression and hopelessness [33] [40]. Cukrowicz et al. [33] underlined the importance of perceived burdensomeness for suicidal ideation in a community sample of older adults. Perceived burdensomeness contributes additional variance beyond the known risk factors of hopelessness and depression. Cukrowicz et al. [33] used a measure of hopelessness as a construct to predict suicide and suicidal ideation. In their first regression analysis Jahn et al. [31] demonstrated that suicidal ideation was associated with depressive symptoms, which relationship was significant. A second regression analysis was performed to determine the significance of the path between depressive symptoms and the mediational variable perceived burdensomeness. A third analysis was conducted in which suicidal ideation was regressed onto the mediational variable, revealing that perceived burdensomeness significantly predicted suicidal ideation. However, the authors did not find that burdensomeness mediated depressive symptoms and suicidal ideation. Further examination indicated that perceived burdensomeness accounted for $68.3 \%$ of the relationship between depressive symptoms and suicidal ideation. Although the study by Mellqvist et al. [35] stated that three-quarters of the participants who had a low Sense of Coherence (SOC) acknowledged hopelessness, the results did not reveal a significant relationship between hopelessness and low SOC. Dennis et al. [37] found a relationship between hopelessness and loneliness during the past five years, but that the Beck Hopelessness Scale was inappropriate for an elderly population.

\subsubsection{The Struggle Due to Poor Social Integration}

Poor social integration such as disagreement with others, loss, lack of social support, shrinking social networks and too little time with children and grandchildren leads to increased suicidal ideation [30] [32] [34] [35]. Rowe et al. [30] revealed that poor "social interaction patterns" and "perceptions of social support" were significantly related to suicidal ideation. Perceptions of social support were analysed to explore their associations with suicidal ideation. The participants' responses to the social support items were dichotomized to "some of the time" versus "most of the time" and "somewhat dissatisfied" versus "satisfied". With the exception of "Knowing what is going on with family and friends", all items were associated with suicidal ideation. Harrison et al. [32] demonstrated that old age was characterized by interpersonal losses and chronic interpersonal difficulties as well as shrinking social networks. The suicidal depressed elderly individuals reported significantly higher levels of aggression and ambivalence compared with their non-depressed peers. Lack of perceived social support was a significant variable in the relationship between chronic interpersonal difficulties and suicidal behaviour. Mellqvist et al. [35] described that too little time spent with children was associated with a fourfold increase in low SOC, while a fivefold increase was noted for too little time spent with grandchildren. Social factors that increased SOC were time spent with children, time spent with grandchildren and having moved house in the past five years. Szanto et al. [34] found several indicators of poor social functioning in suicide attempters. The participants reported disagreements with others, hostility in relationships and a perceived lack of social support. Their social networks were small. They were less likely to talk to their children, had fewer close friends and did not do 
any voluntary work. Thus, attempted suicide in later life seems to be associated with disruptive interpersonal relationships and social isolation.

\subsubsection{The Strain of Physical Illness and Old Age}

The strain of physical illness and old age was associated with suicidal ideation in several studies [31] [32] [36] [41]. Heisel and Flett [31] found significant associations for risk factors such as depression and perceived physical health problems. The participants exhibited relatively low severity of suicide ideation, low to moderate depression and moderate to high psychological well-being. Harrison et al. [32] revealed that the burden of physical illness differed across groups, as non-depressed elderly individuals had lower levels of physical illness. Suicidal and non-suicidal depressed participants had similar levels of depression severity, but those who were suicidal reported the onset of depression at an earlier age. Saias et al. [36] found that depression was strongly related to death ideation. Factors associated with death ideation were chronic illness and being old, especially over 84 years. The results of the logistic regression analysis by Rushing et al. [41] revealed that the only significant predictor of a suicide attempt was age, thus increasing age was associated with greater probability of suicide attempts.

\subsubsection{Negative Aspects of Religious Activity}

Heisel and Flett [31] found a significant association between meaning in life and religiosity as well as between religious activity and responses to the question "Are you a religious person?" indicating greater perception among participants who considered themselves religious. Those reporting a higher frequency of religious activity exhibited significantly more suicidal ideation, an unexpected finding related to both attendance at weekly services and daily religious practice. Daily conduct of religious rituals was associated with increased suicidal ideation, while weekly attendance at religious services was marginally associated with increased suicidal ideation [31].

\subsection{Protective Factors}

\subsubsection{A sense of Belonging}

A sense of belonging was found to protect against suicide [32] [38] [39]. Vander horst \& McLaren [38] stated that their sample had low levels of suicidal ideation, normal levels of depression as well as average levels of social support and sense of belonging. Participants who reported higher levels of depression were more likely to be single with lower social support and sense of belonging. Participants with higher suicidal ideation frequently revealed significantly lower social support and sense of belonging, although latter did not predict depression. Those who had more social support reported less suicidal ideation. McLaren et al. [39] indicated that a high sense of belonging is a protective factor related to lower levels of depression and suicidal ideation. In addition, more severe depression is associated with higher levels of suicidal ideation. However, suicidal ideation is similar in women with a sense of belonging, irrespective of level of depression. In contrast, for women with a low sense of belonging, the level of depression is important as high levels are associated with high suicidal ideation. Harrison et al. [32] reported that suicidal depressed elderly persons had the lowest levels of belonging, tangible support and self-esteem. Suicidal and non-suicidal depressed elderly individuals had lower scores than their nondepressed peers, although the difference was not statistically significant.

\subsubsection{Maintaining Social Dignity}

Maintaining social dignity was reported as important. Heisel and Flett [31] revealed a negative association between self-acceptance and loss of social dignity. Their results suggest that psychological well-being protects against suicidal ideation, while at the same time confirming previous findings pertaining to despair about life's demands and the benefit of achieving a sense of control over one's life. Heisel and Flett [31] findings were consistent with predicted negative associations between psychological well-being and suicidal ideation. It seems important to emphasize the need for older adults to remain connected with others and maintain a positive selfimage.

\subsubsection{Satisfaction with Relationships and Feeling Useful}

Satisfaction with social relationships included a feeling of being useful, personal growth and self-acceptance, 
which were described as a protection against suicide [30] [31]. Rowe et al. [30] demonstrated that the six "perceptions of social support" items were significant. The social support items that remained in the model included "Satisfaction with relationships with family and friends" and "Feeling useful to family and friends". "Satisfaction with relationships" and "Feeling useful" remained significantly associated with suicidal ideation in the final model. The two specific components of support associated with suicidal ideation were not being satisfied with relationships and not feeling useful to others. Heisel and Flett [31] demonstrated that decreased suicidal ideation was significantly associated with positive relationships, personal growth and self-acceptance. Their findings supported the hypothesized negative associations between suicidal ideation and number of children, subjective religiosity, well-being and perceived meaning in life.

\subsubsection{Positive Aspects of Religious Activity}

Religious activity was reported to be a protection against suicide [41]. Rushing et al. [41] stated that a higher frequency of church attendance or public religious activity was significantly related to the decreased suicidal ideation. The results revealed that a lower frequency of church attendance, less perceived social support and poorer self-rated physical health were significant predictors of suicidal ideation. The findings provide evidence that opportunities for social support achieved by church attendance partly account for the relationship between religiosity and lower suicide risk. None of the other social support scales predicted suicidal ideation. Perceived social support mediated the relationship between public religious activity and suicidal ideation. However, none of the religious indicators were associated with reports of previous suicide attempts [41].

\section{Discussion}

The aim of this study was to identify psychosocial risk and protective factors in suicidal older persons. The research question was: What psychosocial risk and protective factors for suicidal older persons are found in the literature?

Being a burden to others increases depression and hopelessness, thus constituting a greater risk of suicide in older persons [33] [40]. Being a burden to others or perceived burdensomeness has been considered an important factor when determining suicide risk in older adults and an explanation for why depression sometimes leads to suicide [44]. The two main components of perceived burdensomeness are liability and self-hate [45]. Being a burden includes less fear of death, increased tolerance of physical pain and being troubled by traumatic memories as well as past experiences [12]. Risk of suicide in depressed older persons was caused by a sense of hopelessness [33] [40]. Thus an association between perceived burdensomeness, depression and suicidal ideation seems to exist [46] [47]. However, it is important to bear in mind that not all depressed persons experience suicidal ideation, while some individuals who report suicidal ideation do not suffer from depression [8]. Nevertheless, in previous studies depression has been described as a risk factor for an escalation of suicidal ideation [24] [48].

The struggle due to poor social integration comprised a struggle against others, a poor social network and lack of social support, all of which increased the risk of suicide [30] [32] [34] [35]. These findings are supported by Durkheim's [49] early observations on social integration. A poorly integrated social network, loneliness and lack of support from service providers hindered integration into the community. Previous research has suggested that successful ageing includes a sense of self-confidence thanks to integration into small, closely knit social networks [50]. Lack of social support and problems in social relationships were associated with increasing suicidal experiences [51]-[53]. Thus elderly persons' psychosocial requirement for a sense of well-being and to be needed is more important than the number of people in their social network. In everyday life the quality of social support can be affected by the degree of dependency and interdependency between parties [16] [17]. Older persons feared becoming increasingly dependent on family, desired a guardian and wished to be independent. The links between material support and death ideation can be explained by the fear of becoming increasingly dependent, thus leading to a higher risk of suicide [54]. Perceived lack of social support in elderly depressed persons was described as increasing guilt, worthlessness and distorting the perception of available support [55]. Such distorted perceptions can lead to a lack of ability to show emotions, which can impair the capacity to experience social support [9]. Social cognition seems to be a prerequisite for the ability to communicate, collaborate and show empathy. Emotional difficulties can influence the social and cognitive dimensions of depression as well as causing a sense of hopelessness in suicidal adults [56]. Poor communication skills can be related to difficulties 
in recognizing emotions, thus contributing to social and mental health problems, described as psychopathology [57] [58].

The strain of physical illness and old age was associated with suicidal ideation [31] [32] [36] [41]. Physical health problems have been reported as increasing the risk of suicide in elderly persons [8] [35] [52] [53]. The importance of assessing the risk of suicidal ideation among older adults struggling with health problems has been described in previous research [31]. In the study by Holm et al. [16], the participants suffered from depression and various physical health problems. They reported experiencing a sense of living with stigma and longed to be taken seriously by the healthcare system. In addition, they had a sense of living in a war zone.

Negative aspects of religious activity. Heisel and Flett [31] revealed an unexpected association between heightened suicidal ideation and increased frequency of religious activities and rituals. According to Braam et al. [59], one explanation can be that high levels of religious observance among secular older adults are associated with severe depression. They may believe that they have no hope of being saved and the fear of being alone can become stronger, especially when depressed. Previous studies revealed that depressed elderly persons struggle with 'relational baggage' [60]. Their self-management ability should be strengthened based on an understanding of their situation, perspectives and vulnerability.

A sense of belonging was described as a protection against suicide [32] [38] [39]. It can be related to an experience of being valued in relationships, being independent as well as the ability to feel cared for and care for others [45]. However, some researchers have criticized individual aspects of this model [54] [61]. Previous research has indicated that males report a lower sense of belonging than females [39] and that the relationship between sense of belonging and depression is stronger for women than for men.

Maintaining social dignity involved self-acceptance. A sense of well-being can protect against suicidal ideation [31]. Human dignity is described as a human being's freedom, which is tied to the responsibility of being human [62]. Social dignity can be understood as part of human dignity and the responsibility we all have for each other. Relationships and interactions with other people are essential as all human beings have the same need to be treated with decency and respect [63]. Frankl's [64] concept of meaning in life seems to protect against despair and suicidal contemplation, thus can facilitate suicide resiliency among people at risk. However, a future orientation may be less relevant to elderly persons, as in old age the perception of meaning in life may turn from future possibilities to past accomplishments, which corresponds to the successful resolution of Erikson's [65] integrity of ego.

Satisfaction with relationships and feeling useful was associated with personal growth and self-acceptance [30] [31]. The findings must be seen from the perspective of elderly persons receiving nursing care in their homes, a time in which they are often confronted with physical, emotional and social changes that are likely to be overwhelming for them and their families. Requiring assistance in their home from "strangers" may elicit feelings of dependency, loss of autonomy or shame. One needs to expand the elderly persons' possibility to talk about issues such as thoughts of death because they are less likely to report suicidal experiences [18]. Elderly persons may have "normal" thoughts of death due to the burden of functional disability and social isolation. Healthcare professionals should engage them in discussion, particularly about their perception of lack of social support, thus providing an opportunity to uncover suicidal ideation. Satisfaction with social relationships is an issue of concern because the perception of social support can be important for uncovering suicidal ideation. Social relationships can function as a 'safety net' and protection during stressful life events such as functional decline, physical and emotional pain or the death of a spouse.

Positive aspects of religious activity were seen as a protection against suicide [31] [41]. Motivating elderly persons to engage in religious activities seems to increase opportunities for social support, which may serve as a buffer against suicidal ideation. A recent literature review indicated that religious and spiritual factors, social cohesion and prosocial behaviour prevented suicide among African Americans [66]. However, cultural minorities can find meaning in religion, which is not the case in elderly adults in white cultures [67]. The fact that social support is related to a sense of belonging, as stated by Joiner [13], can partly explain why religious activity decreases suicidal ideation. As social support appears to decrease mental distress and suicidal ideation, religious activitycan sometimes protect against suicide [68].

\section{Limitations of the Included Studies}

Risk of bias will be discussed in this section, as suggested by Schneider et al. [29] and Polit and Beck [27]. Bias 
is defined as influence that produces a distortion in the results, thus threatening validity and trustworthiness [27]. Five of the included studies have a cross-sectional design, one a longitudinal design [36] and one is described as a case-control study (see Table 1). Descriptive/explorative, correlation, cross-sectional, retrospective, cohort and longitudinal studies can employ an observational design. The studies that have no exact description of design can be designated correlation [40] and descriptive studies [38] [39] [41], which means that these authors employed an observational design. Observational designs can have limitations in their ability to determine "causality" [29], which was mentioned as a limitation in six studies [30] [32] [34] [39]-[41]. The implications of studies with an observational design could be weakened by the fact that participants can change over time. Polit and Beck [69] called this the "history and/or maturity threat". Using one group as described by six studies [30] [31] [35] [38]-[40], could be affected by the history threat, thus increasing bias. A longitudinal design typically requires the participants to retrospectively summarize the extent to which they employed various strategies over a long period and is more likely to produce inaccurate results due to memory bias, compared to measurements that focus on shorter time periods. However, none of the included studies stated that the retrospective design could decrease validity and/or trustworthiness. Six studies described how the lack of prospective data could make it difficult to know exactly what was being investigated and that the small number of significant findings might be a product of the long-term retrospective nature of some participants' reports. Six studies described that future research requires prospective [35] [40] and/or longitudinal data [30] [32] [33] [41]. A prospective design starts with a presumed cause and continues with a presumed effect [69]. Prospective studies are needed to determine the relevance of the findings [34] [35].

All the included studies used self-reports as measurements. According to Shadish et al. [70], self-reports can increase the likelihood of response bias. Heisel and Flett [31] discussed a potential limitation in terms of reliability and validity as a result of using a single item measurement that might be problematic among older adults with hearing impairments, as it could increase the possibility of misunderstanding an item. None of the included studies mentioned self-reports as problematic for validity. McLaren et al. [39] found a limitation if there was a possibility that the results had been confounded by common method variance. Jahn et al. [40] mentioned that all self-report measures might not be as sensitive to a full range of symptoms compared to a clinician-administered interview measure. A weakness was that two of these studies lacked references to methodology [39] [40].

Statistical power depends on sample and effect size, while non-significant implications must be interpreted with caution [29] [70]. Heisel and Flett [31] stated that their findings are limited by the cross-sectional methodology and the largely homogeneous cultural sample. The non-significant findings in two of the studies can be related to selection bias [34] [35]. Mellqvist et al. [35] stated that their results were no longer significant after adjustment for sex, age and major depression. Failure to show significance was described as due to lack of power. However, this information was not related to the methodological literature. Six studies have a relatively small sample size from 80 - 126 (Table 2), but did not mention selection bias as a limitation. Three studies used a control or comparison group while nine employed only one group (Table 2). The limitation of using only one group is not mentioned as leading to a risk of bias in these studies. Bias is one of the major limitations of a case control study due to inability to control confounding variables that influence the outcome [71].

\section{Limitation of This Review}

A limitation of this review is the fact that four of the studies come from the USA, one from Canada, five from Europe and two from Australia (see Table 1). The different cultures in these parts of the world must be taken into consideration; for example, other countries might have a different way of registering psychosocial risk and protective suicidal behaviour in clinical settings. Further studies in other countries are recommended, where the researchers need to strengthen the design, validity and reliability of the quantitative studies.

The studies examined included a broad spectrum of content, outcome measurements and statistical analyses across different time periods, making a meta-synthesis appropriate [26]. The search strategy could be a limitation, as the possibility of excluding relevant studies is ever present. The number of studies published is increasing and new evidence could easily change the relevance of a review in terms of dependability, which refers to the stability (reliability) of data and conditions over time [27]. A thematic analysis can have limitations in exploring data [43].

The aim was to identify psychosocial risk and protective factors in suicidal older persons based on the literature. However, Holopainen et al. [42] suggested that one can never be sure that all relevant studies are included 
in such a systematic review. There is always a possibility that some important aspect has not been found. In order to ensure trustworthiness, the authors tried to avoid bias by not focusing on one study at the expense of another, as recommended by Pope et al. [43].

\section{Conclusion}

This review shows that psychosocial risk factors are dominated by depression, physical illness, the ageing process and social factors. The context of suicidal older persons receiving home healthcare service may create a "vulnerable psychosocial state" with stressful psychosocial life events including physical illness and a changed social network. The fact that protective factors are solely related to social factors should be taken into consideration in future prevention studies. Community administration and leadership must develop contexts favourable to social and community participation of suicidal older persons, thus increasing their social dignity. As this review reveals, the assessment of perceived burdensomeness can be important for making decisions about suicide risk.

\section{Acknowledgements}

We want to thank Gullvi Nilsson and Monique Federsel for reviewing the English language.

\section{Sources of Funding}

Part of the study was supported by grants from the Research Council of Norway, "Chronic Disease ManagementImplementation and coordination of healthcare systems for depressed elderly persons” (NFR, No. 204238/V50) and Department of Health Science, Stord/Haugesund University College, Norway.

\section{References}

[1] World Health Organisation (2009) Prevention of Mental Disorders and Suicide. Policies and Practices for Mental Health in Europe-Meeting the Challenges. World Health Organization Suicide Prevention (SUPRE), Geneva. http://www.who.int/mental_health/prevention/suicide/suicideprevent/en/

[2] Fässberg, M.M., van Orden, K.A., Duberstein P., Erlangsen, A., Lapierre, S., Bodner, E., Canetto, S.S., De Leo, D., Szanto, K. and Waern, M. (2012) A Systematic Review of Social Factors and Suicidal Behavior in Older Adulthood. International Journal of Environment Research Health, 9, 722-745.

[3] De Leo, D., Padoani, W., Scocco, P., Lie, D., Bille-Brahe, U., Arensman, E., Hjelmeland, H., Crepet, P., Haring, C., Hawton, K., Lonnqvist, J., Michel, K., Pommereau, X., Querejeta, I., Phillipe, J., Salander-Renberg, E., Schmidke, A., Fricks, S., Weinacker, B., Tamesvary, B., Wasserman, D. and Faria, S. (2001) Attempted and Completed Suicide in Older Subjects: Results from the WHO/ESURO Multicentre Study of Suicidal Behaviour. International Journal of Geriatric Psychiatry, 16, 300-310. http://dx.doi.org/10.1002/gps.337

[4] Conwell, Y., van Orden, K. and Caine, E.D. (2011) Suicide in Older Adults. Psychiatric Clinic in North America, 34, 451468. http://dx.doi.org/10.1002/gps.337

[5] Oyama, H., Sakashita, T., Ono, Y., Got, M., Fujita, M. and Koda, J. (2008) Effect of Community-Based Intervention Using Depression Screening on Elderly Suicide Risk: A Meta-Analysis of Evidence from Japan. Community Mental Health Journal, 44, 311-320. http://dx.doi.org/10.1007/s10597-008-9132-0

[6] Conwell, Y. and Thompson, C. (2008) Suicidal Behavior in Elder. Psychiatric Clinic of North America, 31, 333-356. http://dx.doi.org/10.1016/j.psc.2008.01.004

[7] Lapierre, S., Erlangsen, A., Waern, M., De Leo, D., Oyama, H., Scocco, P. and Quinnett, P. (2011) A Systematic Review of Elderly Suicide Prevention Programs. Crisis, 32, 88-98. http://dx.doi.org/10.1027/0227-5910/a000076

[8] Erlangsen, A., Jeune, B., Bille-Brahe, U. and Vaupel, J.W. (2004) Loss of Partner and Suicide Risks among Oldest Old: A Population-Based Register Study. Age Ageing, 33, 378-383. http://dx.doi.org/10.1093/ageing/afh128

[9] Talseth, A.G., Gilje, F. and Norberg, A. (2003) Struggling to Become Ready for Consolation: Experience of Suicidal Patients. Nursing Ethics, 10, 614-662. http://dx.doi.org/10.1191/0969733003ne651oa

[10] Kjølseth, I., Ekeberg, Ø. and Steihaug, S. (2009) Why Do They Become Vulnerable When Faced with the Challenges of Old Age? Elderly People Who Committed Suicide, Described by Those Who Knew Them. International Psychogeriatrics, 21, 903-912. http://dx.doi.org/10.1017/S1041610209990342

[11] Rurup, M.L., Pasman, H.R.W., Goedhart, J., Deeg, D.J.H., Kerkhof, A.J.F.M. and Onwuteaka-Philipsen, B.D. (2011) Understanding Why Older People Develop a Wish to Die: A Qualitative Interview Study. Crises, 32, 204-216.

[12] Holm, A.L., Lyberg, A., Berggren, I., Cutcliffe, J. and Severinsson, E. (2014) Shadows from the Past: The Situated 
Meaning of Being Suicidal among Depressed Older People Living in the Community. Crises, 35, 253-260. http://dx.doi.org/10.1027/0227-5910/a000259

[13] Joiner Jr., T.E., Van Orden, K.A., Witte, T.K. and Rudd, M.D. (2009) The Interpersonal Theory of Suicide: Guidance for Working with Suicidal Clients. American Psychological Association, Washington DC. http://dx.doi.org/10.1037/11869-000

[14] Alexopoulos, G.S., Reynolds III, C.F., Bruce, M.L., Katz, I.R., Raue, P.J., Mulsant, B.H., Oslin, D.W. and Ten Have, T. (2009) Reducing Suicidal Ideation and Depression in Older Primary Care Patients: 24 Month Outcomes of the PROSPECT Study. American Journal of Psychiatry, 166, 882-890. http://dx.doi.org/10.1176/appi.ajp.2009.08121779

[15] Ünutzer, J., Tang, L., Oishi, S., Katon, W., Williams Jr., J.W., Hunkeler, E., Hendrie, H., Lin, E.H., Levine, S., Grypma, L., Steffens, D.C., Fields, J. and Langston, C., IMPACT Investigators (2006) Reducing Suicidal Ideation in Depressed Older Primary Care Patients. Journal American Geriatric Social, 54, 1559-1556.

[16] Holm, A.L., Lyberg, A. and Severinsson, E. (2014) Living with Stigma: Depressed Elderly Persons Experiences of Physical Health Problems. Nursing Research and Practice, 2014, 1-8. http://dx.doi.org/10.1155/2014/527920

[17] Holm, A.L., Lyberg, A., Berggren, I., Åström, S. and Severinsson, E. (2014) Social Capital and Depressive Ill- HealthAn Evaluative Approach to the Implementation of the Chronic Care Model (CCM). Open Journal of Nursing, 4, 683694. http://www.scirp.org/journal/ojn

[18] Holm, A.L., Lyberg, A., Berggren, I., Åström, S. and Severinsson, E. (2014) Going around in a Circle: A Norwegian Study of Suicidal Experiences in Old Age. Nursing Research and Practice, 2014, 1-9. http://dx.doi.org/10.1155/2014/734635

[19] Carli, V., Mandelli, L., Zaninotto, L., Iosue, M., Hadlaczky, G., Wasserman, D., Hegerl, U., Värnik, A., Reisch, T., Pfuhlmann, B., Maloney, J., Schmidtke, A., Seretti, A. and Sarchiapone, M. (2013) Serious Suicidal Behaviors: Socio-Demographic and Clinical Features in a Multinational, Multicenter Sample. Nordic Journal of Psychiatry, 68, 4452. http://dx.doi.org/10.3109/08039488.2013.767934

[20] Van Orden, D.A. and Conwell, Y. (2011) Suicides in Late Life. Current Psychiatry Reports, 13, 234-241. http://dx.doi.org/10.1007/s11920-011-0193-3

[21] Bartels, S.J., Coakely, E., Oxman, T.E. Constantino, G., Oslin, D., Chen, H., Zubritsky, C., Cheal, K., Durai, U.N., Gallo, J.J., Llorente, M. and Sanchez, H. (2002) Suicidal and Death Ideation in Older Primary Care Patients with Depression, Anxiety, and at Risk Alcohol Use. American Journal of Geriatric Psychiatry, 10, 417-427. http://dx.doi.org/10.1176/appi.ajgp.10.4.417

[22] Yip, P.S.F., Chi, I., Chiu, H., Wai, K.C., Conwell, Y. and Caine, E. (2003) A Prevalence Study of Suicide Ideation among Older Adults in Hong Kong SAR. International Journal of Geriatric Psychiatry, 18, 1056-1062. http://dx.doi.org/10.1002/gps.1014

[23] Clarke, D.E., Colatonio, A., Heslegrave, R., Rhodes, A., Links, P. and Conn, D. (2004) Holocaust Experience and Suicidal Ideation in High-Risk Older Adults. American Journal of Geriatric Psychiatry, 12, 65-74. http://dx.doi.org/10.1176/appi.ajgp.12.1.65

[24] Awata, S., Seki, T., Koizumi, Y., Sato, S., Omori, K., Kuriyama, S., Arai, H., Nagatomi, R., Matsuoka, H. and Tsuji, I. (2005) Factors Associated with Suicidal Ideation in an Elderly Urban Japanese Population: A Community-Based, Cross-Sectional Study. Psychiatry Clinical Neuroscience, 59, 327-336. http://dx.doi.org/10.1111/j.1440-1819.2005.01378.x

[25] Grant, M. and Booth, A. (2009) A Typology of Reviews: An Analysis of 14 Review Typesand Associated Methodologies. Health Information and Libraries Journal, 26, 91-108. http://dx.doi.org/10.1111/j.1471-1842.2009.00848.x

[26] Jesson, J., Matheson, L. and Lacey, F. (2011) Doing Your Literature Review: Traditional and Systematic Techniques. SAGE, London.

[27] Polit, D.F. and Beck, C.T. (2012) Nursing Research Generating and Assessing Evidence for Nursing Practice. Wolters Kluwer/Lippincott Williams \& Wilkins, Philadelphia.

[28] Prisma Checklist (2009) http://www.prisma-statement.org/2.1.2\%20-\%20PRISMA\%202009\%20Checklist.pdf

[29] Schneider, Z., Whitehead, D., Elliott, D., Lobiondo-Wood, G. and Haber, J. (2007) Nursing \& Midwifery Research Methods and Appraisal for Evidence-Based Practice. Mosby, Elsevier, New York.

[30] Rowe, J.L., Conwell, Y., Schulberg, C. and Bruce, M.L. (2006) Social Support and Suicidal Ideation in Older Adults Using Home Healthcare Services. American Journal of Geriatric Psychiatry, 14, 758-766. http://dx.doi.org/10.1097/01.JGP.0000218324.78202.25

[31] Heisel, M.J. and Flett, G.L. (2008) Psychological Resilience of Suicide Ideation among Older Adults. Clinical Gerontologist, 31, 51-70. http://dx.doi.org/10.1080/07317110801947177

[32] Harrison, K.E., Domborski, A.Y., Morse, J.Q., Houck, P., Schlernitzauer, M., Reynolds III, C.R. and Szanto, K. (2010) 
Alone? Perceived Social Support and Chronic Interpersonal Difficulties in Suicidal Elders. International Psychogeriatrics, 22, 445-454.

[33] Cukrowicz, K.C., Van Orden, K.A., Cheavens, J., Ragain, R.M. and Cook, R.L. (2011) Perceived Burdensomeness and Suicide Ideation in Older Adults. Psychology and Aging, 26, 331-338. http://dx.doi.org/10.1037/a0021836

[34] Szanto, K., Dombrovski, A.Y., Sabakian, B.J., Mulsant, B.H., Houck, P.R., Reynolds, C.F. and Clark, L. (2012) Social Emotion Recognition, Social Functioning, and Attempted Suicide in Late-Life Depression. The American Journal of Geriatric Psychiatry, 20, 257-265. http://dx.doi.org/10.1097/JGP.0b013e31820eea0c

[35] Mellqvist, M., Wiktorsson, S., Joas, E., Östling, S., Skoog, I. and Waern, M. (2011) Sense of Coherence in Elderly Suicide Attempters: The Impact of Social and Health-Related Factors. International Psychogeriatrics, 23, 986-993. http://dx.doi.org/10.1017/S1041610211000196

[36] Saias, T., Beck, F., Bodard, J., Guignard, R. and du Roscoät, E. (2012) Social Participation, Social Environment and Death Ideations in Later Life. PloS ONE, 7, 1-8. http://dx.doi.org/10.1371/journal.pone.0046723

[37] Dennis, M., Wakefield, P., Molloy, C., Andrews, H. and Friedman, T. (2005) Self-Harm in Older People with Depression: Comparison of Social Factors, Life Events and Symptoms. The British Journal of Psychiatry, 186, 538-539. http://dx.doi.org/10.1192/bjp.186.6.538

[38] Vanderhorst, R.K. and McLaren, S. (2005) Social Relationships as Predictors of Depression and Suicidal Ideation in Older Adults. Ageing \& Mental Health, 9, 517-525. http://dx.doi.org/10.1080/13607860500193062

[39] McLaren, S., Rapson, G. and Van der Horst, R.K. (2007) The Association of Depression and Sense of Belonging with Suicidal Ideation among Older Adults: Applicability of Resiliency Models. Suicide and Life-Threatening Behavior, 37, 89-102. http://dx.doi.org/10.1521/suli.2007.37.1.89

[40] Jahn, D.R., Cukrowicz, K.C., Linton, K. and Prabhu, F. (2010) The Mediating Effect of Perceived Burdensomeness on the Relation between Depressive Symptoms and Suicide Ideation in a Community Sample of Older Adults. Aging \& Mental Health, 15, 214-220. http://dx.doi.org/10.1080/13607863.2010.501064

[41] Rushing, N.C., Corsentino, E., Ham, J.L., Sachs-Ericsson, N. and Steffens, D.C. (2012) The Relationship of Religious Involvement Indicators and Social Support to Current and Past Suicidality among Depressed Older Adults. Aging \& Mental Health, 17, 366-374. http://dx.doi.org/10.1080/13607863.2012.738414

[42] Holopainen, A., Hakulinen-Viitanen, T. and Tosavainen, K. (2008) Systematic Review-A Method for Nursing Research. Nurse Researcher, 6, 72-83. http://dx.doi.org/10.7748/nr2008.10.16.1.72.c6754

[43] Pope, C., Mays, N. and Popay, J. (2007) Synthesizing Qualitative and Quantitative Health Evidence: A Guide to Methods. McGraw-Hill Open University Press, Maidenhead.

[44] Chochinow, H.M., Hack, T., Hassard, T., Kristijanson, I.J., McClement, S. and Harlos, M (2005) Understanding the Will to Live in Patients Nearing Death. Psychosomatics, 46, 7-10. http://dx.doi.org/10.1176/appi.psy.46.1.7

[45] Van Orden, K.A., Witte, T.K., Cukrowicz, K.C., Braithwaite, S.R., Selby, E.A. and Joiner, T.E. (2010) The Interpersonal Theory of Suicide. Psychological Review, 117, 575-600. http://dx.doi.org/10.1037/a0018697

[46] Brown, S.L. and Vinokur, A.D. (2003) The Interplay among Risk Factors for Suicidal Ideation and Suicide. The Role of Depression, Poor Health, and Loved Ones' Messages of Support and Criticism. American Journal of Community Psychology, 32, 131-141. http://dx.doi.org/10.1023/A:1025659210192

[47] Wilson, K.G., Graham, I.D., Viola, R.A., Chater, S., de Faye, B.J., Weaver, L.A. and Lachance, J.A. (2004) Structured Interview Assessment of Symptoms and Concerns in Palliative Care. Canadian Journal of Psychiatry, 49, 350-358.

[48] Preville, M., Boyer, R., He Bert, R., Bravo, G. and Seguin, M. (2005) Correlates of Suicide in the Older Adult Population in Quebec. Suicide and Life-Threatening Behavior, 35, 91-105. http://dx.doi.org/10.1521/suli.35.1.91.59269

[49] Durkheim, E. (1966) Suicide: A Study in Sociology. Free Press, New York.

[50] Lang, F.R. and Carstensen, L.L. (2002) Time Counts: Future Time Perspective, Goals, and Social Relationships. Psychological Aging, 17, 125-139. http://dx.doi.org/10.1037/0882-7974.17.1.125

[51] Duberstein, P.R., Conwell, Y., Conner, K.R., Eberly, S. and Caine, E.D. (2004) Suicide at 50 Years of Age and Older: Perceived Physical Illness, Family Discord and Financial Strain. Psychological Medicine, 34, 137-146. http://dx.doi.org/10.1017/S0033291703008584

[52] Duberstein, P.F., Conwell, Y., Conner, K.R., Eberly, S., Evinger, J.S. and Caine, E.D. (2004) Poor Social Integration and Suicide: Fact or Artifact? A Case-Control Study. Psychological Medicine, 34, 1331-1337. http://dx.doi.org/10.1017/S0033291704002600

[53] Harwood, D.M., Hawton, K., Hope, T., Harriss, L. and Jocoby, R. (2006) Life Problem and Physical Illness as Risk Factors for Suicide in Older People: A Descriptive and Case-Control Study. Psychological Medicine, 36, 1265-1274. http://dx.doi.org/10.1017/S0033291706007872

[54] Wiktorsson, S., Marlow, T., Runeson, B., Skoog, I. and Waern, M. (2011) Prospective Cohort Study of Suicide At- 
tempters Aged 70 and above: One-Year Outcomes. Journal of Affective Disorder, 134, 333-340. http://dx.doi.org/10.1016/j.jad.2011.06.010

[55] Szanto, K., Houck, B.H.P.R., Dew, M.A., Dombroski, A., Pollock, B.G. and Reynolds, C.F. (2007) Emergence, Persistence, and Resolution of Suicidal Ideation during Treatment of Depression in Old Age. Journal of Affective Disorder, 98, 153-161. http://dx.doi.org/10.1016/j.jad.2006.07.015

[56] Lee, L., Harkness, K.I., Sabbagh, M.A. and Jacobson, J.A. (2005) Mental State Decoding Abilities in Clinical Depression. Journal of Affective Disorder, 86, 247-258. http://dx.doi.org/10.1016/j.jad.2005.02.007

[57] Kornreich, C., Phillippot, P., Foisy, M.L., Blairy, S., Raynaud, E., Dan, B., Hess, U., Noêl, X., Peic, I. and Verbanck, P. (2002) Impaired Emotional Facial Expression Recognition Is Associated with Interpersonal Problems in Alcoholism. Alcohol, 37, 394-400. http://dx.doi.org/10.1093/alcalc/37.4.394

[58] Ruffman, T., Henry, J.D., Livingstone, V. and Phillips, L.H. (2008) A Meta-Analytic Review of Emotion Recognition and Aging: Implications for Neuropsychological Models of Aging. Neuroscience \& Biobehavioral Reviews, 32, 863881. http://dx.doi.org/10.1016/j.neubiorev.2008.01.001

[59] Braam, A.W., Deeg, D.J.H., Poppelaars, J.L., Beekman, A.T.F. and van Tilburg, W. (2007) Prayer and Depressive Symptoms in a Period of Secularization: Patterns among Older Adults in the Netherlands. The American Journal of Geriatric Psychiatry, 15, 273-281. http://dx.doi.org/10.1097/JGP.0b013e31802d0ae8

[60] Holm, A.L., Lyberg, A., Berggren, I., Lassenius, E. and Severinsson, E. (2013) Older Persons’ Lived Experiences of Depression and Self-Management. Issues in Mental Health Nursing, 34, 757-764. http://dx.doi.org/10.3109/01612840.2013.809829

[61] Gunn III, J.F., Lester, D., Haines, J. and Williams, L. (2012) Thwarted Belongingness and Perceived Burdensomeness in Suicide Notes.Crisis, 33, 178-181. http://dx.doi.org/10.1027/0227-5910/a000123

[62] Alvsvåg, H., Bergland, Å. and Førland, O. (Red) (2013) Nødvendig omveier. En vitenskapelig antologi til Kari Martinsens 70-årsdag, Cappelen Damm Akademisk, Oslo. (In Norwegian)

[63] Jacobson, N. (2007) Dignity and Health: A Review. Social Science \& Medicine, 64, 292-302. http://dx.doi.org/10.1016/j.socscimed.2006.08.039

[64] Frankl, V.E. (1971) The Will to Meaning: Foundations and Applications of Logotherapy. A Psychotherapy Which Teaches That Man Is Free to Shape His Own Character. Souvenir Press Ltd., London.

[65] Erikson, E.H. (1963) Childhood and Society. 2nd Edition, Norton, New York.

[66] Utsey, S.O., Hook, J.N. and Stanard, P. (2007) A Re-Examination of Cultural Factors That Mitigate Risk and Promote Resilience in Relation to African American Suicide: A Review of the Literature and Recommendations for Future Research. Death Studies, 31, 399-416. http://dx.doi.org/10.1080/07481180701244553

[67] Krause, N. (2003) Religious Meaning and Subjective Well-Being in Late Life. Journal of Gerontology: Social Science, 58B, 160-170. http://dx.doi.org/10.1093/geronb/58.3.S160

[68] Robins, A. and Fiske, A. (2009) Explaining the Relation between Religiousness and Reduced Suicidal Behavior: Social Support Rather than Specific Beliefs. Suicide and Life-Threatening Behavior, 39, 386-395. http://dx.doi.org/10.1521/suli.2009.39.4.386

[69] Polit, D.F. and Beck, C.T. (2010) Essentials of Nursing Research: Appraising Evidence for Nursing Practice. Wolters Kluwer/Lippincott Williams \& Wilkins, Philadelphia.

[70] Shadish, W.R., Cook, T.D. and Campbell, D.T. (2002) Experimental and Quasi-Experimental Designs for Generalized Causal Reference. Houghton Mifflin, Boston.

[71] Melnyk, B.M. and Fineout-Overholt, E. (2005) Evidence-Based Practice in Nursing \& Healthcare: A Guide to Best Practice. Wolters Kluwer Company, Lippincott Williams \&Wilkins, Philadelphia. 